\title{
Learner-controlled selection of tasks with different surface and structural features: Effects on transfer and efficiency
}

Citation for published version (APA):

Corbalan, G., Kester, L., \& van Merrienboer, J. J. G. (2011). Learner-controlled selection of tasks with different surface and structural features: Effects on transfer and efficiency. Computers in Human Behavior, 27(1), 76-81. https://doi.org/10.1016/j.chb.2010.05.026

Document status and date:

Published: 01/01/2011

DOI:

10.1016/j.chb.2010.05.026

Document Version:

Publisher's PDF, also known as Version of record

Document license:

Taverne

Please check the document version of this publication:

- A submitted manuscript is the version of the article upon submission and before peer-review. There can be important differences between the submitted version and the official published version of record.

People interested in the research are advised to contact the author for the final version of the publication, or visit the DOI to the publisher's website.

- The final author version and the galley proof are versions of the publication after peer review.

- The final published version features the final layout of the paper including the volume, issue and page numbers.

Link to publication

\footnotetext{
General rights rights.

- You may freely distribute the URL identifying the publication in the public portal. please follow below link for the End User Agreement:

www.umlib.nl/taverne-license

Take down policy

If you believe that this document breaches copyright please contact us at:

repository@maastrichtuniversity.nl

providing details and we will investigate your claim.
}

Copyright and moral rights for the publications made accessible in the public portal are retained by the authors and/or other copyright owners and it is a condition of accessing publications that users recognise and abide by the legal requirements associated with these

- Users may download and print one copy of any publication from the public portal for the purpose of private study or research.

- You may not further distribute the material or use it for any profit-making activity or commercial gain

If the publication is distributed under the terms of Article 25fa of the Dutch Copyright Act, indicated by the "Taverne" license above, 


\title{
Learner-controlled selection of tasks with different surface and structural features: Effects on transfer and efficiency
}

\author{
Gemma Corbalan $^{\mathrm{a}, *}$, Liesbeth Kester $^{\mathrm{b}}$, Jeroen J.G. van Merriënboer ${ }^{\mathrm{c}}$ \\ a Department of Research and Advice, The Netherlands Institute for Curriculum Development, Enschede, The Netherlands \\ ${ }^{\mathrm{b}}$ Centre for Learning Sciences and Technologies, Open Universiteit in the Netherlands, Heerlen, The Netherlands \\ ' School of Health Professions Education, Maastricht University, The Netherlands
}

\section{A R T I C L E I N F O}

\section{Article history:}

Available online 17 June 2010

\section{Keywords:}

Cognitive load

Learner control

Program control

Structural task features

Surface task features

\begin{abstract}
A B S T R A C T
Surface task features are more salient than structural task features and thus easier to recognize for novices. It is predicted that the more salient the task features the better learners can choose personally relevant and varied tasks, which enhances learning transfer. To investigate this prediction, a $2 \times 2$ factorial experiment with 72 participants studied the effects of control over tasks that differ in their surface features (learner, program) and in their structural features (learner, program). Learner control over the selection of tasks with salient surface features enables learners to select personally relevant and varied tasks. This is believed to yield higher effectiveness (i.e., higher near and far transfer test performance) as well as higher efficiency (i.e., higher transfer test performance combined with lower associated mental effort). Learner control over the selection of tasks with non-salient structural features does not enable learners to select personally relevant and varied tasks and is therefore not expected to yield beneficial effects on learning. The results show positive effects of learner control over the selection of tasks with salient surface features for efficiency on the far transfer test but not for effectiveness. Theoretical and practical implications are discussed.
\end{abstract}

(c) 2010 Elsevier Ltd. All rights reserved.

\section{Introduction}

Learner-controlled instruction allows learners to make selections according to their knowledge, interests, and preferences (Van Merriënboer, Schuurman, De Croock, \& Paas, 2002). Theoretically, learner control enhances learning even when choices are trivial (Cordova \& Lepper, 1996). However, empirical studies report both beneficial and detrimental effects of learner control on learning (Katz \& Assor, 2007). It seems that learner control functions differently depending on what (e.g., task features) is being controlled by whom (e.g., novices, experts), and only works if learners recognize the control that is given to them (Scheiter \& Gerjets, 2007).

This study investigated under which conditions the effects of learner control over the selection of learning tasks are optimized. More specifically, it investigates whether learner control is more effective and efficient when learners select tasks based on their surface than on their structural features.

\subsection{Learner control and surface task features}

Surface features refer to task aspects that are not relevant to reach a solution (e.g., species in inheritance tasks because Mendel's

\footnotetext{
* Corresponding author. Address: P.O. Box 2041, 7500 CA, Enschede, The Netherlands. Tel.: +31534840268.

E-mail address: g.corbalan@slo.nl (G. Corbalan).
}

laws are the same for animals, plants, and humans). They generally are salient even for novices (Chi, Feltovich, \& Glaser, 1981; Gick \& Holyoak, 1987; Quilici \& Mayer, 2002). For example, in inheritance tasks, novices will distinguish tasks dealing with a cat's eye colour from tasks dealing with a pea plant's flower shape. Learners who are aware of the different surface features of the tasks they may select will probably be more aware of their motives for choosing between them (Corbalan, Kester, \& Van Merriënboer, 2006). Since learner control over tasks with different surface features is likely to be perceived by the learners, they may use it to make instruction more personally relevant for them (Katz \& Assor, 2007). Personal relevance has been theorized to facilitate learners to connect new information to their prior knowledge without affecting the way the task is solved (Wouters, Tabbers, \& Paas, 2007). This promotes elaboration, a process which leads to new schemas when new information is integrated and organized with prior knowledge (Van Merriënboer, Kirschner, \& Kester, 2003). This construction of general and abstract schemata is useful for solving new problems containing unfamiliar elements (i.e., transfer). In Ross, Morrison, and O'Dell (1989), students who could choose between four task themes (i.e., sports, medical, educational, abstract) to learn statistics performed better than students receiving prescribed themes. Similarly, in Cordova and Lepper (1996), participants who could generate the names of their spacecraft and their opponent in a computer game on arithmetic outperformed participants who received predetermined names. 
Additionally, learners who recognize the different surface features of the tasks they perform may use these features to select a varied set of tasks. Variations in surface features of tasks that share the same solution steps or structural features help learners see beneath surface features and recognize the solution steps of a task, and allow subsequent classification of new tasks (see Chen \& Mo, 2004). This enhances schema induction and thus fosters transfer (Chen \& Mo, 2004; Quilici \& Mayer, 2002). As Gick and Holyoak (1987) stated "Exposure to instances that vary in surface features will allow people to form generalized rules that are not restricted to overly specialized contexts, thus facilitating transfer" (p. 21).

Summing up, learner-controlled selection of tasks that differ in surface features enables learners to select a varied set of personally relevant tasks which enhances induction and elaboration and, eventually, transfer of learning. In this study, we characterize surface features as the context (i.e., different species and traits) in inheritance tasks.

\subsection{Learner control and structural task features}

Structural features refer to task aspects that are directly relevant to reach a solution (e.g., a solution step such as 'determine the genotype of a parent' in an inheritance task, which is an essential step when solving any inheritance task because it represents the genetic constitution of an organism) (Chen \& Mo, 2004; Gick \& Holyoak, 1987). In contrast to surface features, structural features are often less or not salient for novices (Quilici \& Mayer, 2002). Consequently, it is difficult for novices to perceive the control they are given over the selection of tasks with different structural features. In inheritance tasks, for example, it is difficult for novices to distinguish tasks that require them to determine the genotype of a parent' from tasks that require them to 'determine the phenotype of a parent'. Moreover, these learners will not be aware of any valid motives for choosing between tasks that differ in structural features. Hence, they will not distinguish between tasks that are necessary for learning and tasks that could just as well be omitted. This could negatively influence learning.

Since learner control over the selection of tasks with different structural features will not be perceived as such by the learners, it is practically impossible for them to select a varied set of personally relevant tasks. Consequently, they are not likely to profit from the effects of elaboration and induction on learning transfer. Moreover, learners are not likely to profit from variation in practicing tasks with different structural features which is also considered to have positive effects on learning (Holladay \& Quiñones, 2003). When, in a sequence of practiced tasks, the structural task features vary, repetition of specific structural task features occurs at longer intervals and learners have to retrieve the appropriate schema each time a feature (e.g., solution step) needs to be performed. This variation may result in reconstructive activities that will eventually yield more accessible representations in memory, thus enhancing learning (Van Merriënboer, Kester, \& Paas, 2006).

Summing up, novices do not recognize the structural task features and will not select a varied set of personally relevant tasks when provided with control. Consequently, this type of control is not expected to enhance elaboration, induction and, eventually, learning transfer. In this study, we characterize structural task features as the procedural solution steps learners must complete to solve inheritance tasks.

\subsection{Learner control and cognitive load}

The amount of choice learners exert influences learner control effectiveness. Too much control causes cognitive overload and even experts might experience difficulties in selecting, sequencing, and pacing huge amounts of information (Scheiter \& Gerjets,
2007). Shared control over task selection could solve this problem (Corbalan et al., 2006). In this two-step process, a computer program first selects a subset of tasks with desirable task features (e.g., surface and structural features) based on task features of previously selected tasks (program-control). Second, the learner selects from this subset one task to work on (learner-control). This is hypothesized to avoid the potential pitfall of a too high amount of choice and yet grant some learner control (Corbalan et al., 2006). This study implements shared control to prevent cognitive overload.

This study investigated the effects of learner-controlled selection of tasks that differ in their surface (i.e., context) and structural features (i.e., to-be-completed solution steps) on learning effectiveness (i.e., transfer test performance) and efficiency (i.e., transfer test performance in relation to the mental effort invested to reach this performance). Learner-controlled selection of tasks differing in their surface features enhances learning effectiveness and efficiency because the saliency of those task features enables learners to select a varied set of personally relevant tasks, regardless of who (learner, program) selects the structural features. In contrast, the non-saliency of structural features impedes learners to select a varied set of personally relevant tasks. Hence, we expect no differences between learner and program control over tasks differing in those features. Consequently, when the program selects the surface features, no differences are expected when structural features are selected by the program or by the learner.

\section{Method}

\subsection{Participants}

Seventy-two first-year Dutch secondary school students in the Health Sciences domain (61 females, 11 males; mean age $=17.33$ years; $S D=1.07$ ) participated. A $2 \times 2$ factorial design studied the effects of control over the selection of genetic tasks that differ in their surface (program, learner) and structural (program, learner) features. Participants were randomly assigned to one of the four experimental groups: In the 'surface program-control, structural program-control' condition $(n=18)$ the program selected both the surface and structural task features; in the 'surface programcontrol, structural learner-control' condition $(n=17)$ the program selected the surface features and learners selected the structural features; in the 'surface learner-control, structural program-control' condition $(n=17)$ the learners selected the surface features and the program selected the structural features; and in the 'surface learner-control, structural learner-control' condition $(n=20)$ the learners selected both the surface and structural features of the tasks they performed.

\subsection{Materials}

\subsubsection{Electronic learning environment}

A web-based environment was connected to a database containing a basic introduction, a factual knowledge test, all learning tasks, a transfer test, and mental effort measurements.

\subsubsection{Basic introduction}

It included the main genetic concepts necessary to begin the training (i.e., dominant and recessive genes, homozygous and heterozygous gene pairs, genotype and phenotype) and a representative worked example.

\subsubsection{Factual knowledge test}

It contained eight multiple-choice questions and assessed participants' prior factual knowledge. 


\begin{tabular}{|c|c|c|}
\hline \multicolumn{2}{|c|}{ Surface Task Features } & \multirow{2}{*}{$\begin{array}{c}\text { Structural Task Features } \\
\text { Solution Steps }\end{array}$} \\
\hline Species / Species type & Traits / Part traits & \\
\hline $\begin{array}{c}\text { Humans } \\
\text { (European/African/Asian) }\end{array}$ & $\begin{array}{l}\text { Colour (hair/eyes) } \\
\text { Shape (hair/nose) } \\
\text { Length (nose/lips) }\end{array}$ & \multirow{3}{*}{$\begin{array}{l}\text { (1) Determine the genotype of one parent based on } \\
\text { information of the individual given } \\
\text { (2) Determine the genotype of one parent based on } \\
\text { the given percentage in his/her generation } \\
\text { (3) Determine the genotype of one of the offspring of } \\
\text { the first generation } \\
\text { (4) Determine the genotype based on the information } \\
\text { of the prior partner and related offspring } \\
\text { (5) Draw a Punnett's square by combining the genotype } \\
\text { of the parents } \\
\text { (6) Determine the genotype of the offspring and calculate } \\
\text { their percentage } \\
\text { (7) Determine the phenotype of the offspring and calculate } \\
\text { their percentage }\end{array}$} \\
\hline $\begin{array}{c}\text { Animals } \\
\text { (dog/cat/guinea pig) }\end{array}$ & $\begin{array}{c}\text { Colour (fur/eyes) } \\
\text { Shape (ear/fur) } \\
\text { Length (tail/fur) }\end{array}$ & \\
\hline $\begin{array}{c}\text { Plants } \\
\text { (pea/corn/bean) }\end{array}$ & $\begin{array}{l}\text { Colour (flower/leaf) } \\
\text { Shape (fruit/pod) } \\
\text { Length (axis/fruit) }\end{array}$ & \\
\hline
\end{tabular}

Fig. 1. Composition of the task database.

\subsubsection{Learning tasks}

The database contained 54 completion inheritance tasks (e.g., inheritance of the hair, fur, or leaf colour). Completion tasks present a given state, a goal state, and a partial solution that learners must complete by adding the missing solution steps (Van Merriënboer \& Kirschner, 2007). Learning tasks varied in: (a) the contextual features species and traits (i.e., surface features), and (b) the to-becompleted solution steps (i.e., structural features). In Fig. 1, the first and second columns contain species (e.g., animal, plant) with species types (e.g., cat, pea) and traits (e.g., colour, shape) with trait parts (e.g., fur, tail), and the third column describes the seven solution steps to reach the solution. Steps five, six and seven appeared twice in each task because tasks included two generations of offspring and these steps were required to solve each generation. That is, after solving one generation, the same three steps appeared to solve the next generation. Each completion task contained three to-be-completed solution steps. For instance, if steps one, three, and four had to be completed by the learner, the right solution of the four remaining solution steps, that is, steps two, five, six, and seven was given.

Each participant completed 12 learning tasks. Each correctly completed step scored one point, except for steps five, six and seven, which appeared twice in each task. For these steps each correct answer scored a half point, leading to a total of one point per step. This led to a maximum score of three points per task and of 36 points for the whole training. The reliability of the scores for the learning tasks was $\alpha=.92$ (Cronbach's alpha).

\subsubsection{Task selection}

The first (subset of) task(s) was randomly selected by the program and the subsequent (set of) learning task(s) was/were dynamically selected either by the learner or by the program. Tasks varied depending on how dissimilar the surface and structural features were as compared to the previous task. Regarding the surface features, two levels of dissimilarity were distinguished: (1) low dissimilarity, which contained tasks with either (a) same species, species type, trait, and trait part, or (b) same species and trait but different species type and trait part, and (2) high dissimilarity, which contained tasks with either (a) different species or trait, and different species type and trait part, or (b) different species and trait and different species type and trait part. Regarding the structural features, also two levels of dissimilarity were distinguished: (1) low dissimilarity, which contained tasks with either (a) zero, or (b) one to-be-completed solution steps different from the previous task, and (2) high dissimilarity, which contained tasks with (a) two, or (b) three to-be-completed solution steps different from the previous task. When the surface features were selected by the program, one task with high dissimilarity was presented. When the surface features were selected by the learner, four tasks including each combination of low and high dissimilarity levels were pre- sented, from which the learner selected one. When the structural features were selected by the program, one task with high dissimilarity was presented. When the structural task features were selected by the learner, four tasks including each combination of the low and high dissimilarity levels were presented, from which the learner selected one (see Fig. 2). In the learner-controlled conditions, each task-selection screen prompted the participants to select the species and trait (i.e., surface features) or to select the steps to-be-completed (i.e., structural features). The selection screen always showed four tasks, presented in two rows of two tasks and contained a description of the surface features and a description of the to-be-completed steps.

\subsubsection{Transfer test}

It contained four near and four far transfer tasks. The near transfer tasks were structurally similar to the learning tasks but contained different surface features (i.e., other subjects within the species, for example, fruit flies, and other traits, for example, position of the wings) and determined whether participants were able to apply the learned procedures in the same way as in the learning tasks. The far transfer tasks required participants to flexibly use the learned solution procedures during training to structurally different tasks. The following far transfer tasks were used: (a) a dihybrid crossing task which required two different traits to be treated separately; (b) a family tree task in which participants had to infer the genotype of several of the individuals based on the information given in the tree; (c) a task in which participants had to infer the genotype of an individual from information of the father; and (d) a task with co-dominant genes, that is, genes that are equally strong and both expressed. The maximum score on the near and far transfer test was four points each. Reliability of the tests were, $\alpha=.88$ and $\alpha=.74$ for the near and far transfer test.

\subsubsection{Mental effort}

Mental effort was measured as the "effort required to solve the task" (Paas, Tuovinen, Tabbers, \& Van Gerven, 2003) after each learning and transfer tasks with a one-item 7-point Likert-type scale ranging from 1 (very low effort) to 7 (very high effort). Reliabilities were $\alpha=.98$ for the learning tasks, and $\alpha=.91$ and .86 for the near and far transfer tasks, respectively.

\subsubsection{Efficiency}

Participants' test performance on near and far transfer and mental effort invested during the performance of those tests were combined using the procedure of Paas and Van Merriënboer (1993) to calculate efficiency on near and far transfer. When performance is higher than might be expected on the basis of invested mental effort, the instruction is relatively efficient, and when performance is lower than might be expected on the basis of invested mental effort, the instruction is relatively inefficient. 


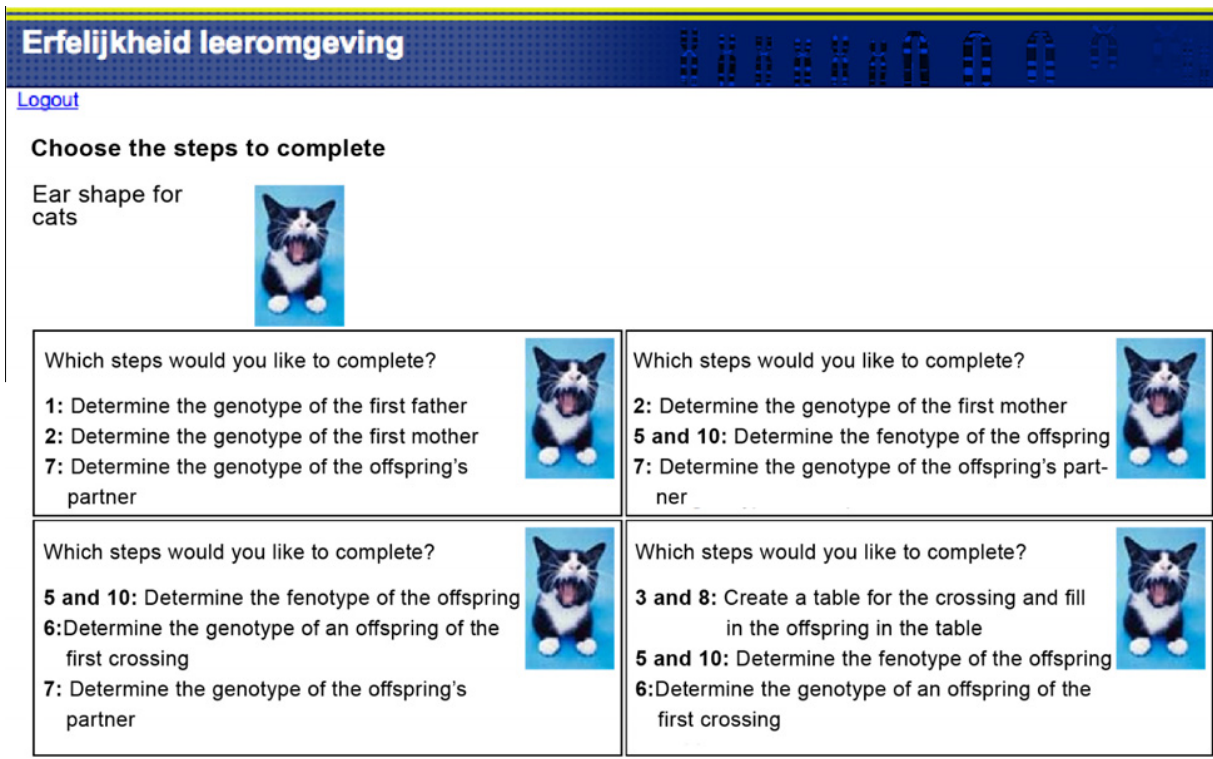

Fig. 2. Example of a task-selection screen in the 'structural learner-control' conditions.

Table 1

Overview of results.

\begin{tabular}{|c|c|c|c|c|c|c|c|c|}
\hline & \multicolumn{4}{|c|}{ Surface program-control } & \multicolumn{4}{|c|}{ Surface learner-control } \\
\hline & \multicolumn{2}{|c|}{$\begin{array}{l}\text { Structural program-control } \\
(n=18)\end{array}$} & \multicolumn{2}{|c|}{$\begin{array}{l}\text { Structural learner-control } \\
(n=17)\end{array}$} & \multicolumn{2}{|c|}{$\begin{array}{l}\text { Structural program-control } \\
(n=17)\end{array}$} & \multicolumn{2}{|c|}{$\begin{array}{l}\text { Structural learner-control } \\
(n=20)^{\mathrm{a}}\end{array}$} \\
\hline & $M$ & SD & $M$ & SD & $M$ & SD & $M$ & SD \\
\hline \multicolumn{9}{|l|}{ Learning phase } \\
\hline Performance $(0-36)$ & 20.42 & 8.63 & 23.09 & 8.45 & 16.76 & 9.25 & 19.08 & 9.11 \\
\hline Mental effort $(1-7)^{\mathrm{b}}$ & 4.51 & 1.68 & 4.97 & 1.03 & 4.76 & 1.68 & 4.32 & 1.47 \\
\hline \multicolumn{9}{|l|}{ Test phase } \\
\hline Performance near transfer $(0-4)$ & 1.67 & 1.44 & 1.62 & 1.43 & 1.71 & 1.33 & 1.72 & 1.14 \\
\hline Performance far transfer $(0-4)$ & 1.39 & 0.94 & 1.16 & 0.76 & 1.46 & 1.22 & 1.48 & 1.13 \\
\hline Mental effort near transfer $(1-7)^{c}$ & 5.01 & 1.76 & 5.50 & 1.13 & 4.35 & 1.58 & 4.35 & 1.39 \\
\hline Mental effort far transfer $(1-7)^{\mathrm{d}}$ & 5.53 & 1.29 & 5.85 & 0.72 & 4.68 & 1.41 & 4.59 & 1.53 \\
\hline \multicolumn{9}{|l|}{ Efficiency } \\
\hline Near transfer & -0.11 & 1.54 & -0.36 & 1.19 & 0.22 & 1.31 & 0.23 & 1.05 \\
\hline Far transfer & -0.19 & 1.20 & -0.51 & 0.71 & 0.30 & 1.34 & 0.37 & 1.31 \\
\hline
\end{tabular}

a $n=19$ in the test phase.

Mean of the measurements collected after each learning task

c Mean of the measurements collected after each near transfer task.

${ }^{d}$ Mean of the measurements collected after each far transfer task.

\subsection{Procedure}

The experiment was completed in a single location and in one single session. In the pre-training phase, participants received the basic introduction and completed the factual knowledge test. Subsequently, participants started the learning phase. Participants were not informed on how the tasks were (pre-) selected. In each learning task, participants could press a continue button after a to-be-completed solution step was solved. The remaining solutions steps until the next to-be-completed solution step appeared. In the test phase, participants completed the transfer test. After each training and test task, mental effort was measured. During the learning and test phases participants could work at their own pace.

\section{Results}

An ANOVA on the prior factual knowledge test revealed no differences between conditions $(F(3,68)<1)$. Hence, results are not likely to be artefacts of prior knowledge differences between conditions. Data analysis included analyses of variance with the between-sub- jects factors control over task selection based on (1) surface task features (program, learner) and (2) structural task features (program, learner). Table 1 shows the mean scores and standard deviations of all dependent variables during the learning and test phases.

\subsection{Learning results}

Due to technical difficulties, eight participants had a missing mental effort value on one of their learning tasks. The missing value was replaced by the participant's own mean mental effort computed over the whole training phase.

For training performance and mental effort, results revealed neither statistically significant main effects nor interaction effects.

\subsection{Test results}

One participant in the 'surface learner-control, structural learner-control' condition had to leave the session earlier and did not perform the transfer test. 


\subsubsection{Test performance}

Results revealed neither statistically significant main effects nor interaction effects.

\subsubsection{Mental effort}

Regarding near transfer, a significant main effect of 'control over task selection based on surface features' was found, $F(1,67)=6.65$, MSE $=14.71, p<.025, \eta_{p}^{2}=.09$. Participants in the 'surface learnercontrol' conditions experienced lower mental effort during the near transfer test than participants in the 'surface program-control' conditions. Regarding far transfer, again a significant main effect of control over task selection based on surface features was found, $F(1,67)=12.01, \mathrm{MSE}=19.75, p<.010, \eta^{2}=.15$. Participants in the 'surface learner-control' conditions experienced lower mental effort during the far transfer test than participants in the 'surface program-control' conditions. No other main or interaction effects were found.

\subsubsection{Efficiency}

A significant main effect of 'Control over task selection based on surface features' was found on the far transfer test, $F(1,67)=6.02$, MSE $=8.32, p<.025, \eta_{p}^{2}=.18$. Efficiency was higher in the 'surface learner-control' conditions than in the 'surface program-control' conditions. No other significant effects were found.

\subsection{Additional analyses}

\subsubsection{Learner and program selections}

To compute the dissimilarity level regarding the surface and structural features of each task, each selected task received zero, one, two, or three points corresponding to the low and high dissimilarity levels for both surface and structural features. For example, a task with different species and trait and different species type and trait part would score three points because it corresponds to the high dissimilarity level of the surface task features. This led to a dissimilarity level of minimally zero points and maximally 33 points (11 task selections). Participants in the 'surface learner-control, structural learner-control' condition selected significantly more different surface than structural features, $t(19)=19.41, p<.001, d=1.16$. Furthermore, in the' surface program-control conditions, the surface features were more varied than in thé surface learner-control conditions, $F(1,68)=67.36$, MSE $=772.62, p<.001, \eta_{p}^{2}=.50$. Similarly, in the' structural program-control conditions, the structural features were more varied than in the structural learner-control conditions, $F(1,68)=202.33, \mathrm{MSE}=5480.19, p<.001, \eta^{2}=.75$.

\section{Discussion}

This study investigated the effects of learner-controlled selection of tasks that differ in their surface and/or structural features on learning effectiveness and efficiency. As hypothesized, efficiency on far transfer was higher when learners selected the surface task features themselves. Presumably, these learners were able to apply the learned solution procedures to solve unfamiliar inheritance tasks more flexibly. However, effectiveness was not higher when students selected tasks with different surface features, although as expected they invested less mental effort on near and far transfer. Probably, having learners select surface features in isolation from the structural features may help them to optimize their allocation of cognitive resources for learning by attending to the selection of surface features first. Additional analyses show that participants in the 'surface learner-control, structural learner-control' condition chose more varied tasks when they selected them on the basis of their surface features. Thus, results show that it is better to give learners the freedom to select tasks with their preferred surface task features. Furthermore, as expected no differences were found for mental effort, effectiveness, and efficiency between learners who could select tasks with different structural features and learners who could not. Additionally, that participants who could select both surface and structural task features performed similarly on transfer than participants who selected only surface features, further supports our assumption that learner control over surface features has a larger impact on learning than learner control over structural features.

Although participants in the 'surface learner-control' conditions invested less mental effort to reach a similar effectiveness than participants in the 'surface program-control' conditions, no differences between these groups were found for efficiency on near transfer. A possible explanation for higher efficiency on far transfer but not on near transfer concerns the general information available in the schemas constructed. This general information is particularly useful to deal with tasks that require learners to flexibly apply the learned solution procedure, but is of less use for familiar tasks that require learners to apply the learned solution procedure similarly to the practiced tasks (Sweller, Van Merriënboer, \& Paas, 1998). Additionally, participants in all conditions were required to direct their attention towards the solution steps. Hence, all participants had the opportunity to compile problem-specific schemas, but only participants in the 'surface learner-control' conditions, who were encouraged to see the connections between tasks, were encouraged to construct generalized schemas. Nevertheless, given the low test scores in this study, any interpretation on the basis of constructed schemata and learning effects should be given cautiously.

Additional analyses revealed that the program selected more varied surface and structural features than the learners. Although the task complexity level was similar in all conditions, participants differed in their learning experiences as a result of their choices. It was argued that variability enhances learning. The fact that the less varied surface features in the learner control conditions still yielded better results, further supports the expected positive effects of learner control over surface features. Another finding that needs to be discussed is why learner control over the non-salient structural features, which yielded low variation, did not yield inferior learning than program control, which presented tasks with dissimilar task features. This might further support the idea that these features are not salient for novices. Another explanation is provided by Gick and Holyoak (1987). The authors hold that initial exposure to relatively similar learning elements (e.g., to-be-completed solution steps) helps establishing generalized rules and more dissimilar elements should only be used to elaborate the rule set once the initial rules have been firmly established and strengthened. Accordingly, early practice of tasks with similar structural features, followed by subsequent exposure to more variable practice, is expected to optimize learning and transfer. In our study, such a sequence occurred in neither the 'structural learner-control' nor the 'structural program-control' conditions.

Our results have several implications for future research. First, differences between novices and experts (who are presumably better able to recognize structural features than novices) should be studied regarding their ability to select a varied set of personally relevant tasks based on structural features. Second, whether cognitive load acts as a mediator between the control exerted and transfer performance should be more explicitly investigated. Third, whether prompting learners to select surface and structural features (e.g., by explicit instruction or giving them feedback on their selections) yields better results should be investigated. Finally, learners' perceptions of the personal relevance of tasks and their motives for the selections they make should be explicitly assessed.

Whereas many studies report efficiency measures and the effects of learner control on surface features, there seem to be no other studies which applied efficiency measures with instructional 
conditions that included learner control over surface features. Another innovative aspect of this study is that the choices presented in the learner-controlled conditions were dynamically adapted to the choices made by the learner in each prior task.

Concluding, this study showed that learner control based on surface features is more beneficial for learning, while learner control based on structural features is not. In this respect, this study complements the attempts of other authors to determine guidelines for implementing learner control (Scheiter \& Gerjets, 2007). This finding is particularly important for instructional designers because educational curricula increasingly use forms of on-demand education, in which learners plan their own learning trajectory.

\section{Acknowledgment}

This research was funded by the Netherlands Organization for Scientific Research (NWO, The Hague, project no.411-02-107-V) and was carried out by the first author during her research at the Open University of the Netherlands.

\section{References}

Chen, Z., \& Mo, L. (2004). Schema induction in problem solving: A multidimensional analysis. Journal of Experimental Psychology: Learning, Memory, and Cognition, 30 583-600.

Chi, M., Feltovich, P., \& Glaser, R. (1981). Categorization and representation of physics problems by experts and novices. Cognitive Science, 5, 121-152.

Corbalan, G., Kester, L., \& Van Merriënboer, J. J. G. (2006). Towards a personalized task selection model with shared instructional control. Instructional Science, 34, 399-422.

Cordova, D. I. \& Lepper, M. R. (1996). Intrinsic motivation and the process of learning: Beneficial effects of contextualization, personalization, and choice. Journal of Educational Psychology, 88, 715-730.
Gick, M., \& Holyoak, J. (1987). The cognitive basis for knowledge transfer. In S. Cormier \& J. Hagman (Eds.), Transfer of learning: Contemporary research and applications (pp. 9-46). San Diego, CA: Academic Press.

Holladay, C. L., \& Quiñones, M. A. (2003). Practice variability and transfer of training: The role of self-efficacy generality. Journal of Applied Psychology, 88, 1094-1103.

Katz, I., \& Assor, A. (2007). When choice motivates and when it does not. Educational Research Review, 19, 429-442.

Paas, F., Tuovinen, J., Tabbers, H., \& Van Gerven, P. W. M. (2003). Cognitive load measurement as a means to advance cognitive load theory. Educational Psychologist, 38, 63-71.

Paas, F., \& Van Merriënboer, J. J. G. (1993). The efficiency of instructional conditions: An approach to combine mental-effort and performance measures. Human Factors, 35, 737-743.

Quilici, J. L., \& Mayer, R. E. (2002). Teaching students to recognize structural similarities between statistics word problems. Applied Cognitive Psychology, 16, 325-342.

Ross, S. M., Morrison, G. R., \& O’Dell, J. K. (1989). Uses and effects of learner control of context and instructional support in computer-based instruction. Educational Technology, Research and Development, 37, 29-39.

Scheiter, K., \& Gerjets, P. (2007). Learner control in hypermedia environments. Educational Psychology Review, 19, 285-307.

Sweller, J., Van Merriënboer, J. J. G., \& Paas, F. (1998). Cognitive architecture and instructional design. Educational Psychology Review, 10, 251-296.

Van Merriënboer, J. J. G., Kester, L., \& Paas, F. (2006). Teaching complex rather than simple tasks: Balancing intrinsic and germane load to enhance transfer of learning. Applied Cognitive Psychology, 20, 1-10.

Van Merriënboer, J. J. G., \& Kirschner, P. A. (2007). Ten steps to complex learning. Mahwah, NJ: Erlbaum.

Van Merriënboer, J. J. G., Kirschner, P. A., \& Kester, L. (2003). Taking the load off a learner's mind: Instructional design for complex learning. Educational Psychologist, 38, 5-13.

Van Merriënboer, J. J. G., Schuurman, J. G., De Croock, M. B. M. \& Paas, F. (2002). Redirecting learners' attention during training: Effects on cognitive load, transfer test performance, and training efficiency. Learning and Instruction, 12, 11-37.

Wouters, P., Tabbers, H. K., \& Paas, F. (2007). Interactivity in video-based models. Educational Psychology Review, 19, 327-342. 